\title{
DESIGN CHARACTERISTICS THAT IMPROVE THE FATIGUE LIFE OF THREADED PIPE CONNECTIONS
}

\author{
J. Van Wittenberghe ${ }^{1}$, P. De Baets ${ }^{1}$, W. De Waele ${ }^{1}$, T. Galle ${ }^{1}$, T.T. Bui ${ }^{2}$ and G. De Roeck ${ }^{2}$ \\ ${ }^{1}$ Ghent University, Laboratory Soete, Belgium \\ ${ }^{2}$ K.U.Leuven, Department of Civil Engineering, Belgium
}

\begin{abstract}
Threaded pipe connections are commonly used to connect risers, tendons, drill pipes and well casing strings. In these applications fatigue resistance plays an important role. A large variety of patented design features exist, all claiming to improve the connection's fatigue life. However, patent documents only contain claims and numerical or experimental data about these connection's performance is generally not published. This makes it hard to make a quantitative comparison between different designs. In this study an overview is given of fatigue resistant threaded connections. Two major methods to improve the fatigue life of a connection were identified. First of all, local stress concentrations can be reduced by optimizing the geometry of the threads. Second the global shape of the connection can be optimized to obtain a more uniform load distribution.

Using a parametric finite element model, different designs were compared. The connections were modelled by a 2D axisymmetric geometry with non-linear material properties and elaborate contact conditions. Selected designs have been subjected to experimental tests in a four-point bending fatigue setup. The experimental tests serve as a validation for the results of the numerical simulations. It was found that the multiaxial stress distribution at the thread roots is the defining factor for the fatigue life of the connection. Nevertheless, these stresses can be changed by the global geometry of the connection. It can be concluded that the fatigue life of threaded connections is determined by a combination of global and local aspects which should both be analysed for fatigue life calculations.
\end{abstract}

Keywords threaded pipe connection, fatigue, patent, experiment, finite element model

\section{FATIGUE RESISTANT THREADED PIPE CONNECTIONS}

\subsection{General trends}

Specialized threaded connections are developed and optimized for the use in dynamic applications. Those fatigue resistant designs are all aimed at reducing the maximum appearing stress peaks in the connection. Throughout the existing patented designs two general trends can be identified to achieve this goal. Firstly, the global box geometry is changed to obtain a more uniform load distribution over the threads and hence reducing the high stresses appearing at the last engaged threads (LET) which are typical for general threaded connections. The second trend to obtain a fatigue resistant connection is to provide a local modified thread shape. By changing the thread profile, the local stress intensity can be reduced and by altering the thread shape or interference over the engaged thread length the load distribution can be additionally optimized.

\subsection{Global box geometry modifications}

In 1961 a new connection was invented by Bodine [1] (illustrated in Figure 1.a). This connection was developed to be used in a sonic well pump tubing string. In this application, important fluctuating axial stresses are introduced by the pumping action. Due to the high load carried by the last engaged thread of the pin, fatigue cracks would develop at this location in conventional connection designs. Bodine's connection however, was constructed in such a way that the loads are distributed more uniformly over the different threads, hereby lowering the concentrated load at the LET of the pin and hence increasing the fatigue life of the entire connection. This improved distribution was obtained by changing the box geometry. In general, the box of the connection has a bigger wall thickness than the pin and is the most rigid part of the connection. However, when reducing the stiffness of the box locally, by applying a groove in its outer surface located over the last engaged threads of the pin, the box is able to elastically deform and to transfer the load more easily to the following threads.

The same idea of local stiffness reductions to redistribute loads has been used ever since in a variety of other patents. In 1963 a string connection with a changed box was patented by Schreier [2]. This connection is shown in Figure 1.b. 


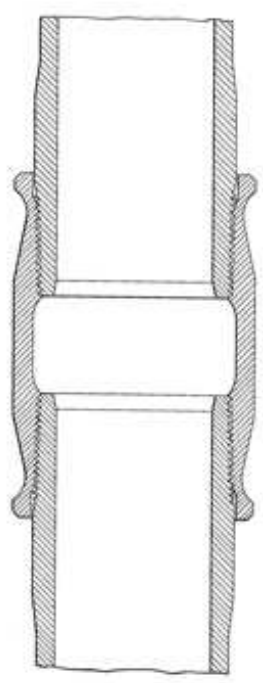

a

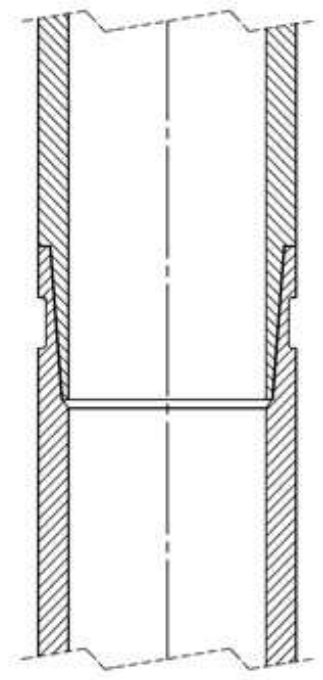

b

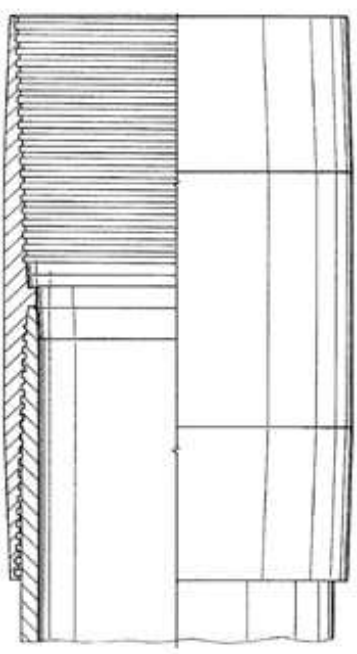

C

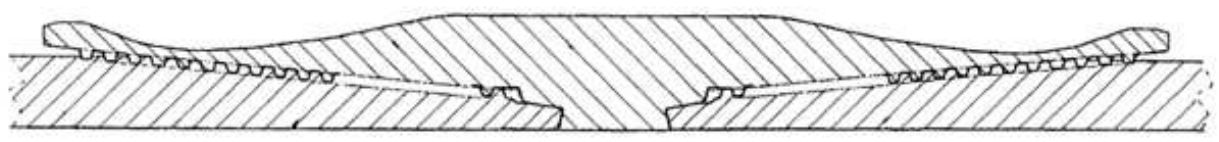

d

Figure 1: Patented box modifications: a) Bodine, 1961 [1], b) Schreier, 1963 [2], c) DeLange and Evans, 2003 [3], d) Verdillon, 2004 [4].

The coupling by DeLange and Evans [3] (Figure 1.c) claims to provide better fatigue performance by changing the so-called stiffness gradient of the recess region of the box. Here the stiffness of the pin or box is equal to the area moment of inertia $I_{z}$ at a certain section. The stiffness gradient $\nabla I_{z}$ is defined by Delange and Evans as the difference in stiffness ratio between pin and box divided by the length $L$ of the chamfer as noted in Eq. (1):

$$
\nabla I_{z}=\frac{\frac{I_{z, 1}}{I_{z, 2}} \frac{I_{z, 3}}{I_{z, 4}}}{L}
$$

In this equation $I_{z, 1}$ and $I_{z, 2}$ are respectively the stiffness of the box and pin section at the end of the box recess. It is specified that the chamfer should start at the location of the last fully engaged thread of the pin. Hence, $I_{z, 3}$ and $I_{z, 4}$ are the stiffness of respectively the box and pin section at LET of the pin, calculated at the pitch line of the threads. Additionally, this design proposes a long engaged thread length, including a thread run-out region where the threads are only partly engaged. This long engaged thread region can also be found in the connection of Verdillon [4] as shown in Figure 1.d. Next to this it uses a waisted groove over the highest loaded threads similar to the original design of Bodine [1]. This connection is commercially available and is named the VAM TOP FE connection. Verdillon added the possibility of filling up the machined groove with an elastic filler material, as long as the stiffness of the used filler is sufficiently lower than the stiffness of the material of the connection.

\subsection{Local thread modifications}

To optimize the connection threads for fatigue purposes, their profile can be changed to reduce the stress intensity at the thread roots. Additional to this, the thread taper, pitch, interference or tolerances can be changed over the engaged threads to modify the load distribution. Since these modifications generally result in complex and hard to produce thread shapes that require very fine tolerances, local thread modifications can be considered as less robust ways to influence the connection's fatigue behaviour. This is because wear or local damage during service can change those tight tolerances and hence eliminate the desired fatigue properties. 


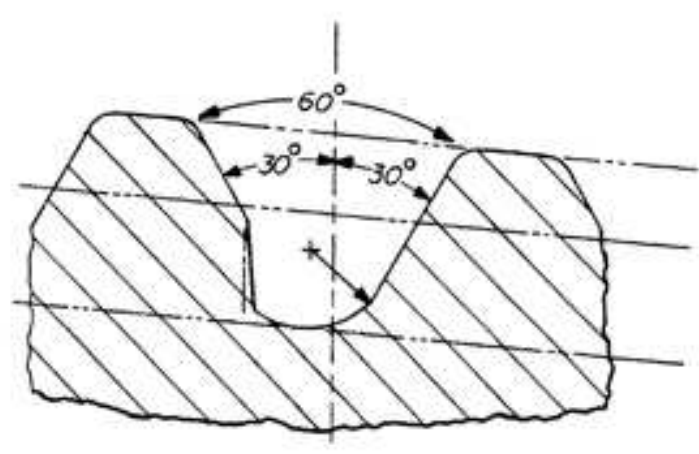

a

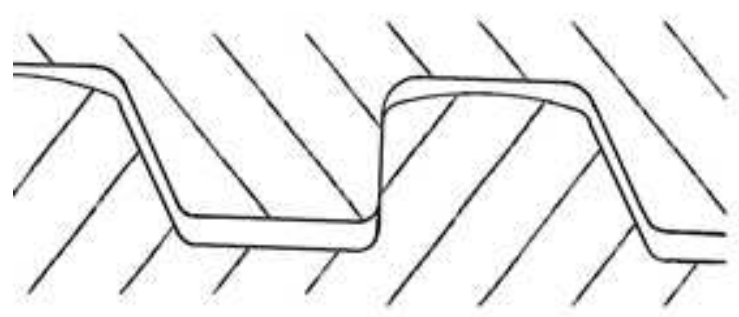

C

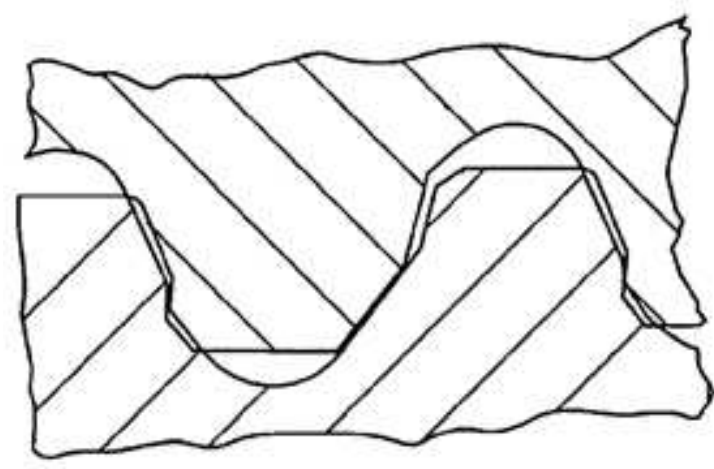

e

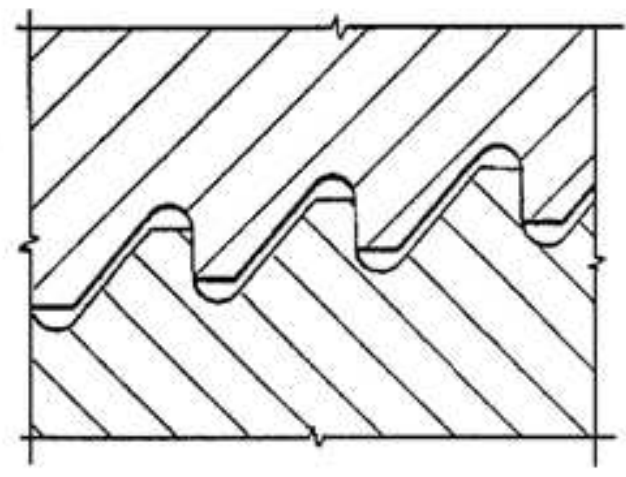

b

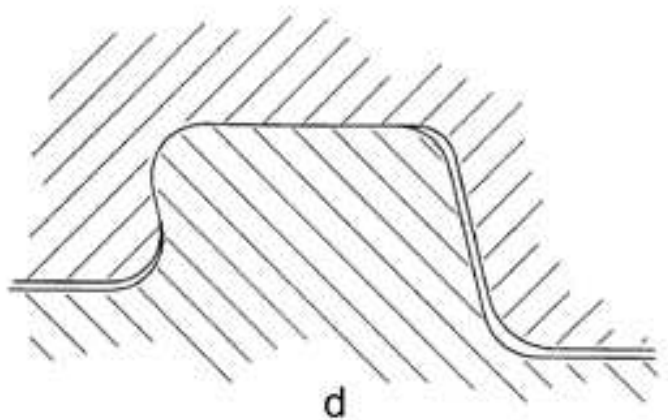

d

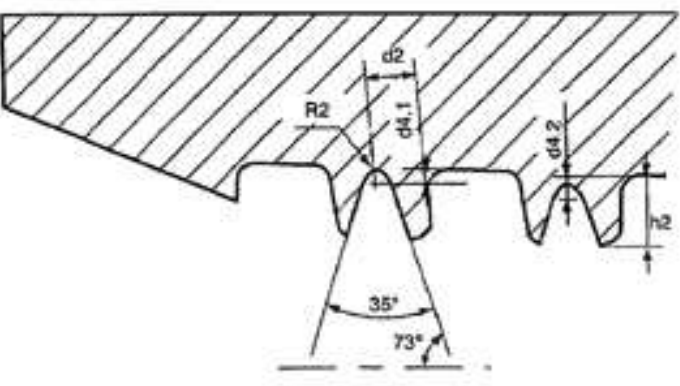

f

Figure 2: Patented thread types: a) Saunders et. al., 1985 [5], b) Gunderson et. al., 1990 [6], c) DeLange et. al., 1999 [7], d) Olivier, 2002 [8], e) Pallini et. al., 2007 [9], f) Noel and Roussie, 2009 [10].

Nevertheless, numerous patented thread modifications exist. The so-called Reed-thread developed by Saunders et. al. [5] as shown in Figure 2.a, is a modified rounded triangular thread. It contains a stress relief groove at the thread root with an increased root radius as compared to standard thread shapes to reduce the stress intensity factor. Additionally the connection contains a pin with a slightly lower taper angle than the box. This results in an artificial change in pitch and radial interference which improves the load distribution.

Both Gunderson et. al. [6] and DeLange et. al. [7] proposed a modified buttress thread with enhanced fatigue properties to be used in connections for risers, tendons or drill applications (see Figure 2.b and c). They both use a zero degree load flank and increased root radii. The zero degree load flank ensures that the axial load on the connection does not produce any significant radial component which would tend to separate the pin from the box.

Worth mentioning is that modified buttress threads also exist with a negative load flank. An example of this can be found in the drill string thread proposed by Olivier [8] as shown in Figure 2.d. The negative load flank locks the connection together and prevents separation of the threads. Next to reducing fretting fatigue failure, this kind of threads are generally more resistant to yielding and overtorque. The thread type of Olivier has improved fatigue properties due to the rounded corners of the load flank.

The irregular thread type for riser connections of Pallini et. al. [9] (Figure 2.e) has an S-shaped load flank that provides a variable load angle depending on the radial position along the contact interface. The thread 
profile uses a combination of thread cuts that vary in shape and pitch to provide load and stab flanks that vary along the axial length of the engaged threads. Due to the changing interference between the threads, the load distribution becomes more uniform over the engaged length. It is obvious that this kind of threads with varying pitch and profile demands extremely tight tolerances and advanced production tools. This results in high production and maintenance costs since connection repairs can only be carried out by specialized workshops. Additionally, the irregular thread shape hinders thread inspection.

Noel and Roussie [10] developed an additional modification of the buttress thread type. But instead of optimizing the root radii, they provided a portion of the threads with an additional groove in the thread crests as can be seen in Figure 2.f. This groove is machined only at the first and last engaged threads. The groove reduces the thread stiffness, which makes that a part of the load is transferred to the subsequent threads. The improved load distribution should result in an increased fatigue life of the connection. Nevertheless, the extra groove in the threads makes inspection and repair of the threads more difficult.

\subsection{Additional fatigue life improving features}

Next to the two general trends of improving the fatigue strength of a connection either by changing the global box shape or the local thread shape, some other techniques are used. The fatigue strength of rounded triangular threads can be improved by cold working the thread roots. For example by rolling the threads after they have been machined into the connection as was shown by Knight et. al. in their study of drill pipe connections [12]. This way compressive residual stresses are introduced at the location where the fatigue cracks tend to initiate, which is beneficial for the fatigue life of the connection. A connection where this introduction of residual stresses is proposed was developed by Benedict et. al. [13].

Stress relief grooves can be used to locally reduce the stiffness of the connection around the first and last engaged thread. This way the load on these locations is partly transferred to the next threads. Since stress relief grooves result in a locally decreased wall, they are only used in upset connections which have a bigger wall thickness than the pipe material. An example of a connection with stress relief grooves is shown in Figure 3.a.

Metal-to-metal surfaces are used as seals to prevent leakage, but when the connection is subjected to dynamic bending loads, those seals can have a beneficial effect on the connection's fatigue life. This is because the metal-to-metal seals also provide structural support for the contacting parts and transmits a part of the bending load. This partly decreases the stresses in the threaded region of the connection. In Figure 3.b an example of such a connection is given [15]. However, as was shown by Santus [16], the metal-to-metal surface is a region susceptible to fretting fatigue damage.

a
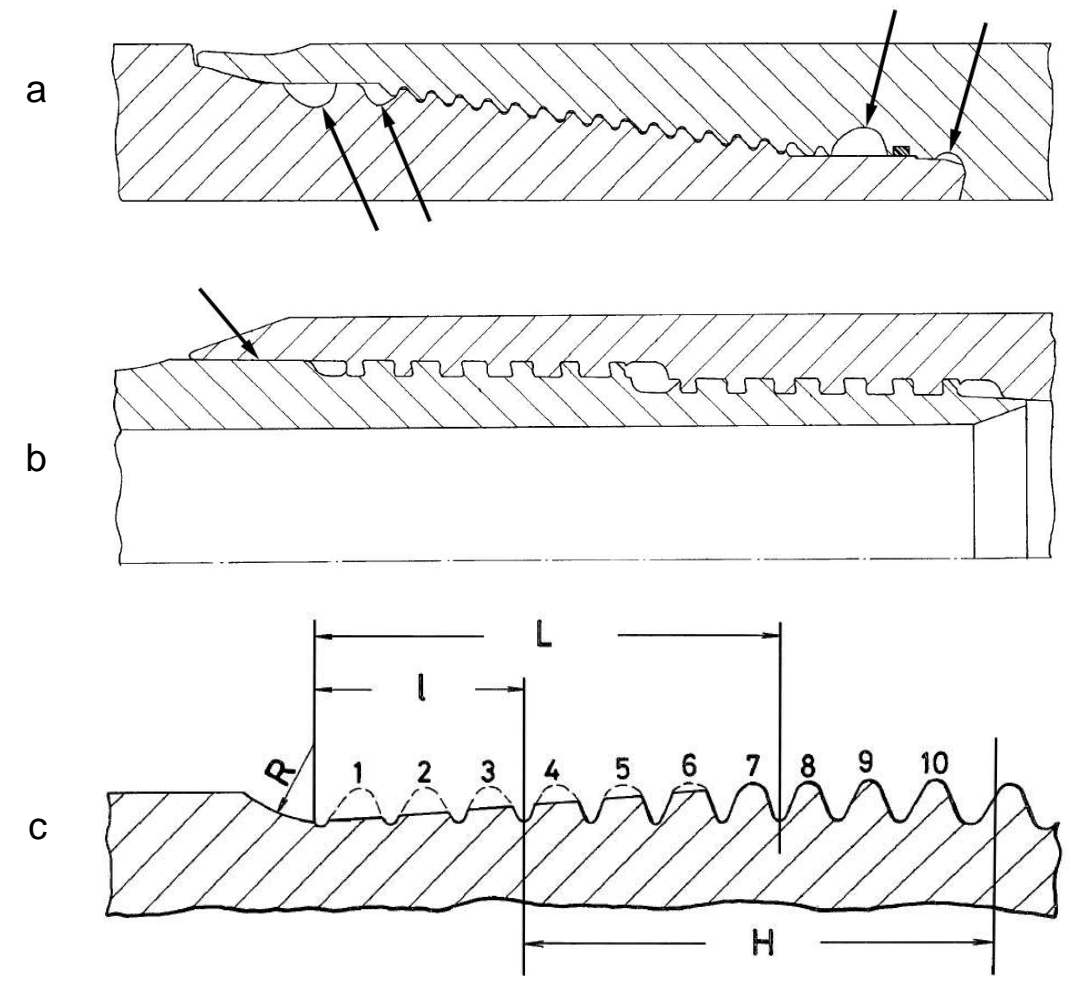

Figure 3: a) Patented stress relief grooves by Pallini et. al. [14], the grooves are indicated by the arrows, b) Metal-to-metal sealing surfaces (indicated by the arrow) [15], c) Patented thread run-out by Nisida et. al [17]. 
A final feature that is claimed to provide better fatigue resistance can be found in the patent of Nisida et. al. [17]. Although this patent is aimed at bolts, it might be applicable to threaded pipe connections as well. As illustrated in Figure 3.c, the last engaged threads of the connection's pin have crests that are cut off. This way the last engaged threads of the box will only be partly engaged. When subjected to axial loads, the last engaged threads of the box will bend and the load will be redistributed to the subsequent threads of the connection. This approach can be considered as a combination of the grooved threads of Noel and Roussie [10] (Figure 2.f) and the long thread run-out of DeLange and Evans [3] (Figure 1.c).

\section{UGENT RESEARCH ON FATIGUE RESISTANCE OF THREADED PIPE CONNECTIONS}

\subsection{Parametric finite element model}

Since patent documents only provide general claims on the fatigue life improvement of a specific design without providing quantifiable data, it is hard to compare the different patented connections. To overcome this problem a parametric finite element program called ThreadGen ${ }^{\mathcal{O}}$ was developed at the Laboratory Soete of Ghent University [18]. This program enables a uniform approach to quantify the fatigue resistance of threaded pipe connections. To simulate the threaded connections a 2D axisymmetric model is used. This is common practice when modelling threaded connections [19],[20] because of the reduced calculation time compared to full 3D models. Next to this it was shown that the results of 3D models are in good agreement with 2D axisymmetric models [21].

The axisymmetric model of an API Line Pipe threaded connection is shown in Figure 4. The model's geometry is built in such a way that all dimensions can be changed parametrically. Only a half box is modelled since a plane of symmetry is assumed at the centreline of the box (see the boundary conditions at the right in Figure 1). The unthreaded pipe body of the pin has a sufficient length to eliminate boundary effects when an external tensile stress is applied at its free end. Besides axial tension loading, the model is also capable of simulating make-up (i.e. the assembly process of pin and box), internal and external pressure.

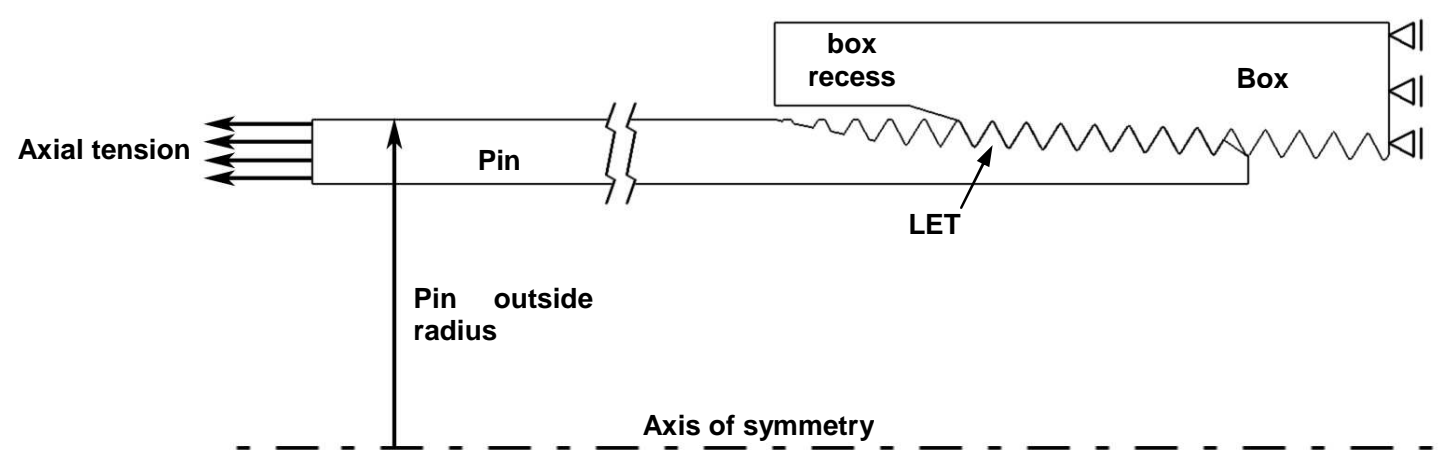

Figure 4: 2D axisymmetric model of an API Line Pipe connection

\section{$2.2 \quad$ Experimental testing}

Based on results from finite element simulations of different coupling designs, specific connection designs were selected for experimental fatigue testing [22]. Two different four-point bending test setups were used as described in [23] to test threaded pipe connections of different sizes. The obtained fatigue data was used to construct S-N curves where the applied dynamic stress amplitude $S_{a}$ is plotted against the number of cycles to failure $N$. In Figure 5 the test data of one of the designs with a predicted enhanced fatigue life by reducing the box wall thickness of an API Line Pipe coupling is compared to the mean curve obtained for a standard API Line Pipe coupling. These tests were carried out on 1" couplings made of API Grade B material at a frequency of $15 \mathrm{~Hz}$ and with a load ratio of $R=0.1$. It can be seen that the optimized design indeed results in an increased fatigue life of the connection since its mean S-N curve lays above the mean curve of the standard connection. For example, the fatigue life increases from $6.6 \cdot 10^{4}$ to $10.7 \cdot 10^{4}$ cycles at a stress amplitude of $20 \%$ of the yield stress and the fatigue limit (defined at $2 \cdot 10^{6}$ cycles) slightly increases from $9.3 \% \sigma_{y}$ to $10.3 \% \sigma_{y}$. 


\subsection{Discussion}

By comparing the results of finite element simulations and the experiments it was found that the connection's fatigue life was not merely a function of the load distribution over the threads. As can be seen in Figure 6 there exists a multiaxial stress distribution over the connection.

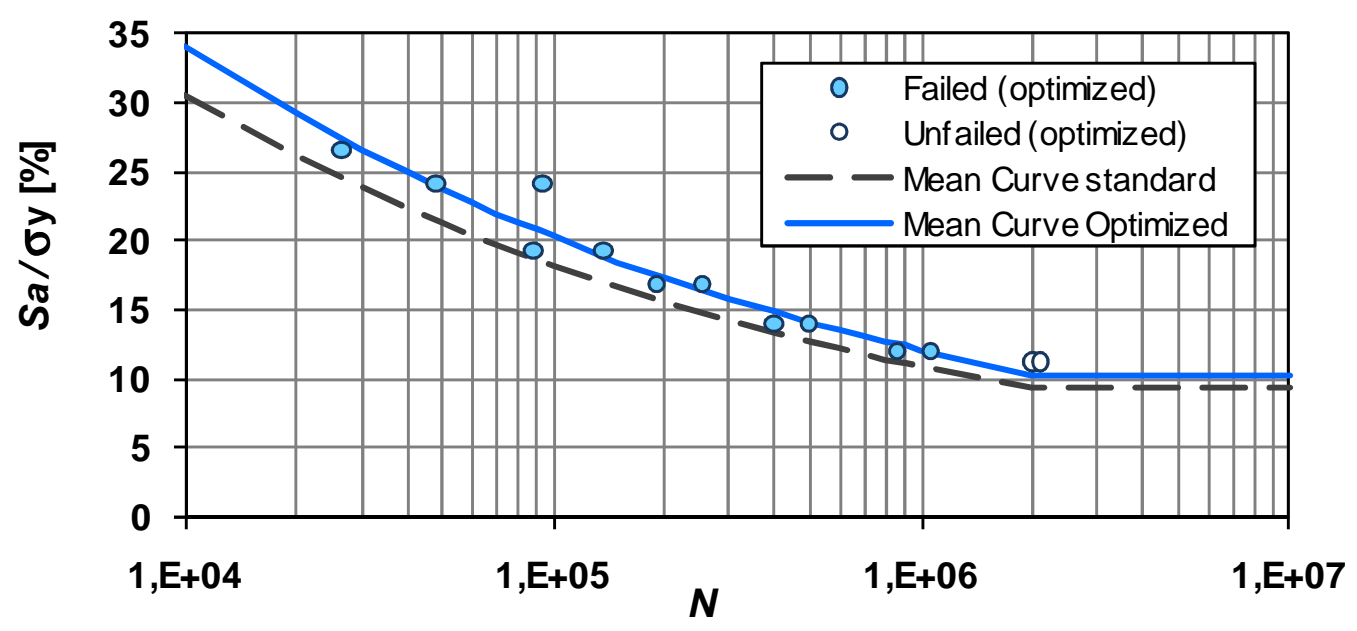

Figure 5: S-N curve from experimental tests, $R=0.1$. The discrete data points correspond to experimental results of the optimized connection.
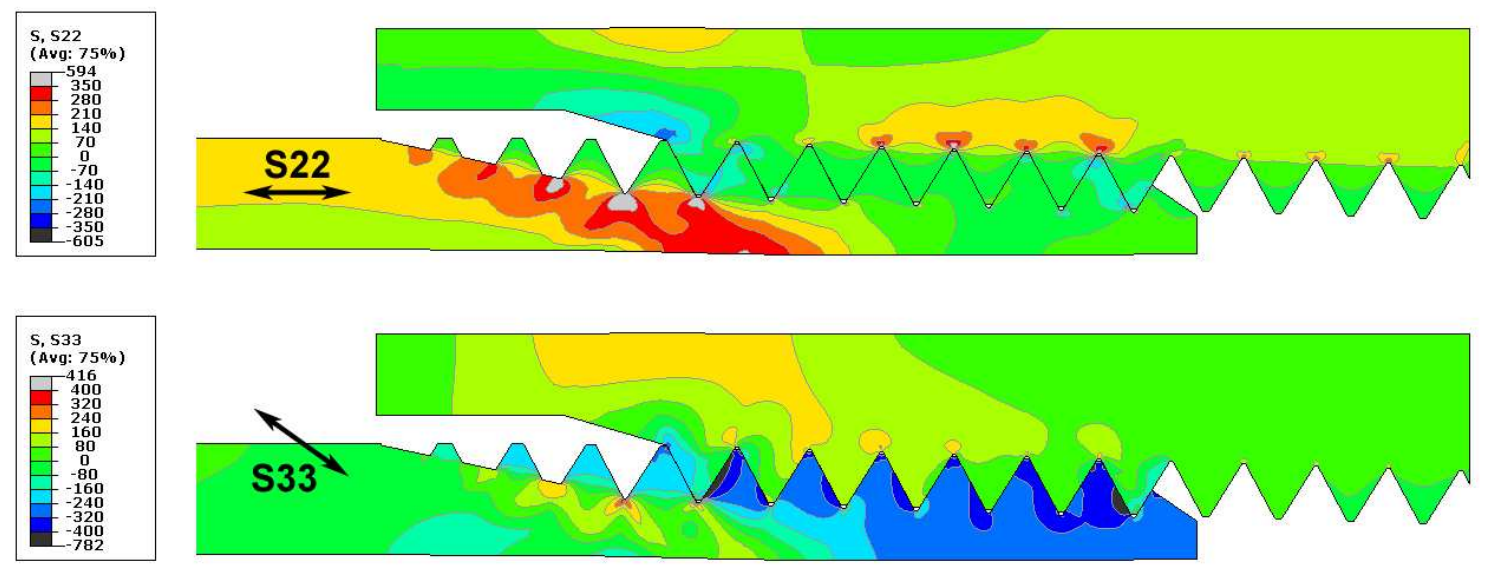

Figure 6: Axial (S22) and hoop stress (S33) distribution over a 1" API Line Pipe connection of API grade B material subjected to a combination of make-up and an axial tensile stress of $150 \mathrm{MPa}$.

In this figure the stress distribution is shown over a standard 1" API Line Pipe connection with elastic-plastic API grade B material properties. As could be expected, the highest stress concentration appears at the LET of the pin. The axial stress component is a result of the applied axial tensile stress, while the compressive hoop stress is a result of the make-up process of the connection which causes the pin to deform plastically. When this multiaxiality is taken into account, the experimentally observed trends in the connection's fatigue life can be explained by a damage evolution law [24].

\section{CONCLUSIONS}

Fatigue life improvement of threaded pipe connections has been extensively studied during the last decades. Numerous patented fatigue resistant connections exist and several are commercially available. However, the information provided in the patent documents are only the general ideas and claims about the resulting performance, but no quantifiable results are published to prove such claims. Additionally, this lack of results makes it impossible to make an objective comparison between different designs.

At Ghent University a methodology was developed to evaluate the fatigue life of threaded pipe connections in a parametric way. This experimentally validated approach takes into account the multiaxiality at the thread roots and is able to predict the fatigue life of a specific connection design. The fatigue life is dominated by the multiaxial stress distribution at the last engaged threads of the connection, but this can be changed by altering the global connection geometry. Hence, when investigating the fatigue behaviour of a threaded pipe design, both global and local aspects should be considered. 


\section{ACKNOWLEDGEMENTS}

The authors would like to acknowledge the financial support of the BOF fund (B/04939) of the Ghent University and of the FWO Vlaanderen (3G022806). Next to this the help of the Laboratory Soete staff and the friendship and collegiality of all researchers is most gratefully acknowledged.

\section{REFERENCES}

[1] Bodine, A.G., Sonic well pump tubing string, United States Patent, US 2992613, 1961.

[2] Schreier, K., Jonction filetée, notamment pour tige de forage, French Patent, FR 1317815, 1963.

[3] De Lange, R.W., Evans, M.E., Threaded and coupled connection for improved fatigue resistance, United States Patent, US 6609735 B1, 2003.

[4] Verdillon, L., Fatigue-resistant threaded bevelled tubular element, United States Patent, US 6752436 B1, 2004.

[5] Saunders, D.D., Kalsi, M.S., Chen, G.S., Tool joint, United States Patent, US 4549754, 1985.

[6] Gunderson, R.H., Burns, J.Q., Fox, S.A., Fatigue-resistant threaded connector, United States Patent, US 4892337, 1990.

[7] De Lange, R.W., Evans, E., Buster, J.L., Threaded Connection for Enhanced Fatigue Resistance, United States Patent, US 5931511, 1999.

[8] Olivier, H.P., Connection, United States Patent, US 6485063 B1, 2002.

[9] Pallini, J.W., Munk, B.N., Riha, J.B., Lyle, R.D., Threaded Pipe Connector, United States Patent, US 2007/0063517 A1, 2007.

[10] Noel, T., Roussie, G., Fatigue-resistant threaded component for tubular threaded joint, United States Patent, US 751534, 2009.

[11] Toscano, R.G., Di Toro N.H.M., Sucker Rod Connection with Improved Fatigue Resistance Formed by Applying Diametrical Interference to reduce Axial Interference, United States Patent, US 7735879 B2, 2010.

[12] Knight, M.J., Brennan, F.P., Dover, W.D., Controlled fatigue design of drillstring threaded connections, Fatigue and Fracture of Engineering Materials and Structures, 26, 1081-1090, 2003.

[13] Benedict, D., Düber, H., Flörke, H., Modular Thread Connection With High Fatigue Resistance, United States Patent, US 7150479 B2, 2006.

[14]Pallini, J.P., Lyle, R.D., Munk, B.N., Threaded Connector, United States Patent, US 6478344 B2, 2002.

[15] Church, K.L., Thread form with multifaced flanks, United States Patent, US 6254146 B1, 2001.

[16] Santus, C., Fretting fatigue of aluminum alloy in contact with steel in oil drill pipe connections, modeling to interpret test results, Int. J. of Fatigue, 30, 677-688, 2008.

[17] Nisida, S., Urashima, C., Masumoto, H., Screwed connection having improved fatigue strength, United States Patent, US 4189975, 1980.

[18] Van Wittenberghe, J., De Baets, P., De Waele, W., Modelling of preloaded threaded pipe connections, Proc. of the 8th Nat. Congress on Theor. and App. Mechanics, 149-156, 2009.

[19] Guangjie, Y., Zhenqiang, Y., Qinghua, W., Zhentong, T., Numerical and experimental distribution of temperature and stress fields in API round threaded connection, Engineering Failure Analysis, 13(8), 1275-1284, 2006.

[20] Sugino, M., Nakamura, K., Yamaguchi, S., Daly, D., Briquet, G., Verger, E., Development of an innovative high-performance premium threaded connection for OCTG, Offshore Technology Conference, OTC20734, 2010.

[21]Van Wittenberghe, J., De Baets, P., De Waele, W., Fatigue life improvement of threaded pipe couplings, ASME Pressure Vessels and Piping Conference, PVP2010-25687, 2010.

[22] Meertens, B., De Baets, P., De Waele, W., Van Wittenberghe, J., Fatigue behaviour of threaded couplings - Experimental Research, Sustainable Construction \& Design, 1, 50-57, 2010. 
[23] Van Wittenberghe, J., De Pauw, J., De Baets, P., De Waele, W., Abdel Wahab, M., Ost, W., De Roeck, G., Bui, T.T., Fatigue Investigation of Threaded Pipe Connections, Sustainable Construction \& Design, 1, 182-189, 2010.

[24]Van Wittenberghe, J., De Pauw, J., De Baets, P., De Waele, W., Wahab, M.A., De Roeck, G., Experimental determination of the fatigue life of modified threaded pipe couplings, Procedia Engineering, 2(1), 1849-1858, 2010. 